\title{
ERISIPELA E CELULITE: DIAGNÓSTICO, TRATAMENTO E CUIDADOS GERAIS
}

\author{
ERYSIPELA AND CELLULITIS: DIAGNOSIS, TREATMENT AND GENERAL CARE
}

\author{
Rita de Cássia Araújo ${ }^{1} *$ Arthur Alexandrino $^{2} *$ Alana Tamar Oliveira de Sousa $^{3}$
}

\section{RESUMO}

Objetivo: sumarizar o diagnóstico, o tratamento e os cuidados gerais prestados aos pacientes acometidos por erisipela ou celulite, conforme a literatura científica. Métodos: Artigo de revisão integrativa, realizada por meio de buscas na Biblioteca Virtual em Saúde e na Pubmed, nas bases de dados Medline e Scopus. Os critérios de inclusão foram: artigos publicados em português, inglês e espanhol, cujos assuntos abordados foram as manifestações clínicas, os exames e os cuidados prestados a pacientes com erisipela ou celulite publicados nos últimos oito anos. Foram excluídos os artigos duplicados nas bases buscadas e que não tratavam do tema. Nove artigos fizeram parte da análise crítica e da sumarização dos dados. Resultados: A erisipela e a celulite são infecções da pele que ocorrem em estágios diferentes. O diagnóstico é baseado nas alterações clínicas e o tratamento é basicamente farmacológico, terapia nutricional e cuidados de enfermagem. Considerações finais: O diagnóstico é puramente clínico e não há como sempre diferenciar erisipela de celulite, já que as manifestações clínicas são semelhantes. $\mathrm{O}$ tratamento é feito, principalmente, com a penicilina e seus derivados, e os cuidados gerais incluíram hidratação e nutrição adequadas, redução do edema e cicatrização das lesões de pele. São necessários mais estudos originais.

Palavras-chave: Erisipela; Celulite; Diagnóstico; Terapêutica; Cuidados de Enfermagem.

\section{ABSTRACT}

Objective: summarize the diagnosis, treatment and general care provided to patients affected by erysipelas or cellulitis, according to the scientific literature. Methods: Integrative review article, performed through searches on the Virtual Health Library and on Pubmed, as well as on the Medline and Scopus databases. The inclusion criteria were: articles published in Portuguese, English and Spanish, where the addressed topic consisted of clinical manifestations, exams and care provided to patients with erysipelas and cellulite, published in the last eight years. We excluded duplicate articles in the searched databases and that did not address the theme. Nine articles made up the critical analysis and data summarization. Results: Erysipelas and cellulite are infections of the skin that occur at different stages. The diagnosis is based on clinical changes and treatment is basically pharmacological, nutritional therapy and nursing care. Final considerations: The diagnosis is merely clinical and there is no way to always differentiate erysipelas from cellulite, since the clinical manifestations are similar. Treatment is mainly performed with penicillin and its derivatives, and general care included appropriate hydration and nutrition, reduction of edema and healing of skin lesions. Further original studies should be performed.

Keywords: Erysipelas; Cellulitis; Diagnosis; Therapeutics; Nursing Care.

\footnotetext{
${ }^{1}$ Enfermeira. Universidade Federal de Campina Grande - UFCG. Cuité, Paraíba, Brasil. E-mail: ritadecassiaaraujo282@ gmail.com. Orcid: https://orcid.org/0000-0003-2152-2513.

${ }^{2}$ Enfermeiro. Mestrando em Saúde Coletiva pela Universidade Federal do Rio Grande do Norte - UFRN. Natal, Rio Grande do Norte, Brasil. E-mail: alexandrinoarthurdm@gmail.com. Orcid: https://orcid.org/0000-0001-5817-4335.

${ }^{3}$ Doutora em Enfermagem. Docente da Universidade Federal de Campina Grande - UFCG. Cuité, Paraíba, Brasil. E-mail: alanatamar@gmail.com. Orcid: https://orcid.org/0000-0002-1683-2851.
} 


\section{INTRODUÇÃO}

As infecções dos tecidos moles ocorrem quando um microrganismo ultrapassa a barreira da pele e compromete o tecido. A erisipela é uma dessas infecções, que atinge a camada superficial da pele e ocasiona uma inflamação considerável dos vasos linfáticos. Sua etiologia é bacteriana, e o principal agente é o Streptococcus $\beta$ hemolítico, do grupo A de Lancefield, geralmente o Streptococcus pyogenes. Também pode ser causada por outras espécies de estreptococos (grupos B, C ou G) ou Staphylococcus aureus e caracteriza-se pelo aparecimento de eritema, dor, edema e rubor, normalmente em membros inferiores (MMII). É menos frequente na face, nas orelhas, no tronco e nos membros superiores (MMSS) ${ }^{(1,2)}$.

Em contrapartida, a celulite é uma infecção da derme reticular e do tecido subcutâneo, cujos agentes etiológicos mais comuns são o Staphylococcus aureus e o Estreptococos $\beta$-hemolíticos ${ }^{(3)}$. Também se manifesta, principalmente, nos MMII, mas pode acometer outras áreas, como os MMSS em mulheres depois de tratamento cirúrgico de câncer de mama ${ }^{(1)}$.

A erisipela pode ser eritematosa (edema e hiperemia), bolhosa (bolhas volumosas e tensas, com líquido não purulento), hemorrágica (hemorragia na pele afetada) e gangrenosa (ulceração

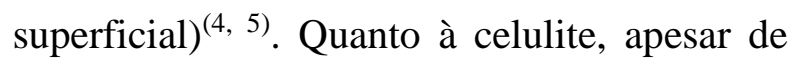
poder surgir bolhas e necrose, ela é classificada como não purulenta e purulenta, quando há drenagem de pus, geralmente relacionado à presença do Staphylococcus aureus $^{(6)}$.

Assim, apesar de as duas condições clínicas serem consideradas distintas, os profissionais ainda têm muita dificuldade de diferenciá-las, especialmente em relação às áreas do corpo acometidas, à profundidade das lesões ${ }^{(1)}$ e às complicações ${ }^{(7)}$.

Essas complicações são trombose venosa profunda (TVP) (menos chances de ocorrer), áreas necrosadas, abscessos, gangrena, fasciíte necrotizante, tromboflebite, glomerulonefrite aguda, septicemia, artrite séptica, endocardite e, em alguns casos, óbito. Estima-se que a doença evolui entre 80 e 90,6\% dos casos, e a mortalidade pode variar de 0,5 a $20 \%$ dos casos, a depender do tipo de antibioticoterapia utilizado no tratamento e da associação com as comorbidades presentes ${ }^{(7)}$.

Nessa perspectiva, é necessário compreender a diferença entre erisipela e celulite, para que o manejo clínico seja feito corretamente em cada doença. Assim, este estudo tem potencial para contribuir com profissionais que estão em diferentes níveis de atenção e que encontram dificuldades para diagnosticar e prestar assistência de qualidade a pacientes que sejam acometidos por uma dessas infecções.

Desse modo, considerando o exposto, o objetivo desta pesquisa é de sumarizar o diagnóstico, o tratamento e os cuidados gerais 
prestados a pacientes acometidos por erisipela ou celulite, conforme a literatura científica.

\section{MÉTODOS}

Trata-se de uma revisão integrativa realizada em seis etapas: 1 - seleção do tema e da questão norteadora; 2 - designação dos critérios de inclusão e exclusão; 3 estabelecimento do conteúdo a ser extraído dos artigos selecionados; 4 - avaliação crítica dos estudos da revisão; 5 - discussão e interpretação dos resultados; 6 - apresentação da revisão e síntese do conhecimento ${ }^{(8)}$.

$\mathrm{Na}$ primeira etapa, delinearam-se o tema e a seguinte questão norteadora: Como a literatura aborda o diagnóstico, os cuidados e o tratamento de pacientes com erisipela e celulite?

Realizou-se uma busca na Biblioteca Virtual em Saúde (BVS) e na Pubmed, nas seguintes bases de dados: Medical Literature Analysis and Retrieval Sistem on-line (Medline) e Scopus. As buscas foram realizadas em abril de 2020, utilizando-se os seguintes descritores em Ciências da Saúde (DeCS) erysipelas e cellulitis, erisipela e celulite, acrescido do operador booleano AND.

Os critérios de inclusão foram: artigos publicados em português, inglês e espanhol, que abordassem como assunto as manifestações clínicas, os exames e os cuidados voltados para os pacientes com erisipela e celulite publicados nos últimos oito anos. Foram excluídos artigos duplicados e que não tratavam do tema.

A Figura 1 expõe a síntese das estratégias utilizadas na identificação dos artigos selecionados para compor esta revisão.

Figura 1 - Diagrama do fluxo da sistematização da busca dos artigos - Cuité, Paraíba, Brasil. 2020.

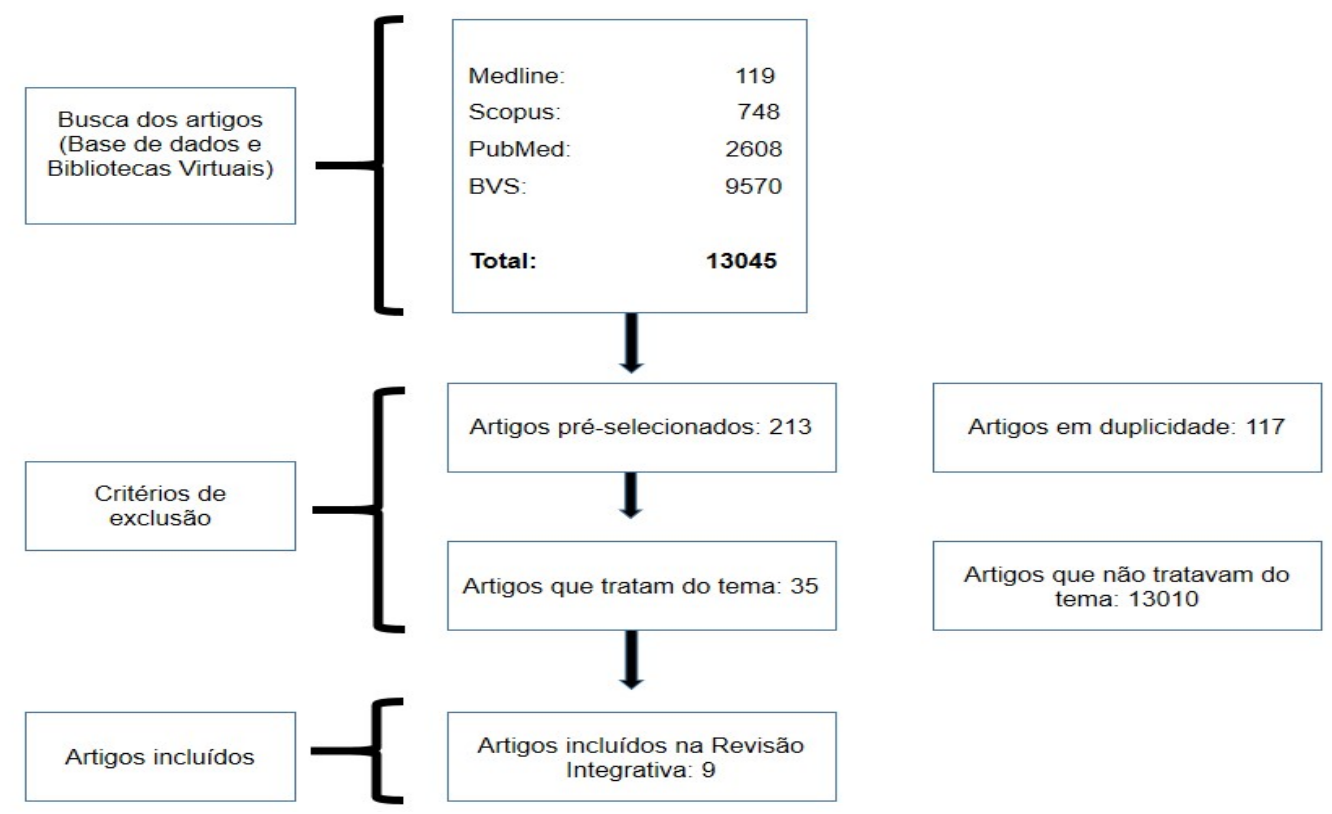

Fonte: Elaborado pelos autores, 2020. 
Os artigos escolhidos foram analisados com base nos critérios de autenticidade, qualidade metodológica e significâncias das informações. Depois de proceder à avaliação crítica dos artigos selecionados e de escolher as informações mais relevantes, elaborou-se um quadro com as informações detalhadas sobre cada estudo com título, periódico, base de dados/ano, objetivo, tipo de estudo, principais resultados e conclusão.
A análise crítica e a síntese dos estudos selecionados foram realizadas de forma descritiva, com subdivisão para as categorias analíticas, incluindo diagnóstico, tratamento e cuidados gerais para os pacientes com erisipela ou celulite.

\section{RESULTADOS}

A amostra, composta de nove artigos, apresentou publicações em 2013 (1), 2014 (2), 2015 (1), 2016 (1), 2017 (2) e 2019 (2). Sete artigos estavam no idioma inglês, e os demais, em português. No Quadro 1, apresentam-se os artigos. 
Quadro 1 - Matriz de discussão dos resultados. 2020.

\begin{tabular}{|c|c|c|c|c|c|c|}
\hline Título & Periódico & $\begin{array}{c}\text { Base de } \\
\text { dados/ Ano }\end{array}$ & Objetivo & Tipo de estudo & Principais resultados & Conclusão \\
\hline $\begin{array}{l}\text { 1. Diagnósticos } \\
\text { e intervenções } \\
\text { de enfermagem } \\
\text { em paciente } \\
\text { com erisipela: } \\
\text { estudo de caso } \\
\text { em hospital de } \\
\text { ensino }\end{array}$ & $\begin{array}{l}\text { Revista } \\
\text { Eletrônica } \\
\text { Gestão e } \\
\text { Saúde }\end{array}$ & $\begin{array}{l}\text { Medline/ } \\
2013\end{array}$ & $\begin{array}{l}\text { Identificar os } \\
\text { diagnósticos e as } \\
\text { intervenções de } \\
\text { enfermagem para } \\
\text { afecções dérmicas } \\
\text { causadas } \\
\text { erisipela bolhosa em } \\
\text { pacientes de uma } \\
\text { Clínica Médica de } \\
\text { um hospital de } \\
\text { ensino na cidade de } \\
\text { Montes Claros. }\end{array}$ & Estudo de caso & $\begin{array}{l}\text { Nesse estudo de caso, a } \\
\text { erisipela se iniciou por } \\
\text { meio de um processo } \\
\text { infeccioso no membro } \\
\text { inferior. Primeiramente, } \\
\text { a pele apresentou-se lisa, } \\
\text { brilhante, vermelha e } \\
\text { quente e passou a } \\
\text { desenvolver bolhas e, } \\
\text { depois, } \\
\text { Realizaram-se } \\
\text { diagnóstico médico, } \\
\text { tratamento farmacológico } \\
\text { e algumas intervenções } \\
\text { de enfermagem. }\end{array}$ & $\begin{array}{l}\text { Foram traçados } \\
\text { diagnósticos de } \\
\text { enfermagem de acordo } \\
\text { com a taxonomia } \\
\text { NANDA. O tratamento } \\
\text { baseou-se } \\
\text { especialmente com o } \\
\text { cuidado da dole, } \\
\text { controle da dor, } \\
\text { farmacoterapia, } \\
\text { estímulo ao sono e } \\
\text { repouso entre outros. As } \\
\text { intervenções } \\
\text { enfermagem resultaram } \\
\text { na melhora do quadro }\end{array}$ \\
\hline
\end{tabular}




\begin{tabular}{|c|c|c|c|c|c|c|}
\hline & & & & & & da paciente. \\
\hline $\begin{array}{l}\text { 2. Comparing } \\
\text { short to } \\
\text { standard } \\
\text { duration of } \\
\text { antibiotic } \\
\text { therapy for } \\
\text { patients } \\
\text { hospitalized } \\
\text { with cellulitis } \\
\text { (DANCE): study } \\
\text { protocol for a } \\
\text { randomized } \\
\text { controlled } \\
\text { trial }\end{array}$ & $\begin{array}{l}\text { BMC } \\
\text { Infectious } \\
\text { Diseases }\end{array}$ & $\begin{array}{l}\text { Scopus/ } \\
2014\end{array}$ & $\begin{array}{l}\text { Comparar em } \\
\text { pacientes } \\
\text { hospitalizados a } \\
\text { segurança e a } \\
\text { eficácia da redução } \\
\text { da antibioticoterapia } \\
\text { para celulite de } 12 \\
\text { para seis dias. }\end{array}$ & $\begin{array}{l}\text { Estudo } \\
\text { multicêntrico, } \\
\text { randomizado, } \\
\text { duplo-cego em } \\
\text { fase de } \\
\text { recrutamento de } \\
\text { pacientes } \\
\text { adultos } \\
\text { admitidos com } \\
\text { celulite (em fase } \\
\text { de coleta) }\end{array}$ & $\begin{array}{l}\text { A celulite confunde-se } \\
\text { com a erisipela e está } \\
\text { entre as infecções mais } \\
\text { frequentes } \\
\text { possibilitam } \\
\text { hospitalização. } \\
\text { pacientes admitidos no } \\
\text { hospital com essa } \\
\text { enfermidade recebem, } \\
\text { inicialmente, o esquema } \\
\text { terapêutico } \\
\text { antibiótico, por via } \\
\text { intravenosa (IV); depois, } \\
\text { utilizam-se antibióticos } \\
\text { orais. }\end{array}$ & $\begin{array}{l}\text { Acredita-se que a } \\
\text { exposição excessiva aos } \\
\text { antibióticos deve ser } \\
\text { controlada, já que seu } \\
\text { uso excessivo } \\
\text { desnecessário } \\
\text { considerado um dos } \\
\text { principais fatores que } \\
\text { contribuem para } \\
\text { resistência. } \\
\text { antibiótico deve } \\
\text { utilizado no menor } \\
\text { período de tempo } \\
\text { possível. }\end{array}$ \\
\hline
\end{tabular}




\begin{tabular}{|c|c|c|c|c|c|c|}
\hline $\begin{array}{l}\text { 3.Practice } \\
\text { Guidelines for } \\
\text { the diagnosis } \\
\text { and } \\
\text { management of } \\
\text { skin and soft } \\
\text { tissue infections: } \\
2014 \text { update by } \\
\text { the Infectious } \\
\text { diseases society } \\
\text { of America }\end{array}$ & $\begin{array}{l}\text { Clinical } \\
\text { Infectious } \\
\text { Diseases }\end{array}$ & $\begin{array}{l}\text { Scopus/ } \\
2014\end{array}$ & $\begin{array}{l}\text { Apresentar o } \\
\text { diagnóstico e o } \\
\text { tratamento adequado } \\
\text { de diversas infecções } \\
\text { da pele e dos tecidos } \\
\text { moles (IPTMs). }\end{array}$ & Diretriz clínica & $\begin{array}{l}\text { As culturas de sangue ou } \\
\text { aspirados cutâneos, } \\
\text { biópsias ou swabs não } \\
\text { são recomendados } \\
\text { rotineiramente para a } \\
\text { avaliação e o tratamento } \\
\text { da erisipela e da celulite. } \\
\text { Indica-se agente } \\
\text { antimicrobiano ativo } \\
\text { contra os estreptococos, } \\
\text { para os casos típicos de } \\
\text { celulite sem sinais } \\
\text { sistêmicos. Para celulite } \\
\text { com sinais de infecção } \\
\text { mais severos, devem-se } \\
\text { utilizar antibióticos } \\
\text { injetáveis. }\end{array}$ & $\begin{array}{l}\text { Com base na avaliação } \\
\text { correta da lesão, o } \\
\text { tratamento é iniciado de } \\
\text { acordo com a situação } \\
\text { do paciente. Podem ser } \\
\text { utilizados antibióticos } \\
\text { sistêmicos e anti- } \\
\text { inflamatórios, e para } \\
\text { pacientes graves, } \\
\text { indica-se cobertura } \\
\text { antimicrobiana } \\
\text { amplo espectro. }\end{array}$ \\
\hline $\begin{array}{l}\text { 4. Diagnosis } \\
\text { and }\end{array}$ & $\begin{array}{l}\text { British } \\
\text { Journal of }\end{array}$ & Pubmed/ & $\begin{array}{l}\text { Analisar as diretrizes } \\
\text { para o diagnóstico, o }\end{array}$ & Revisão & $\begin{array}{l}\text { A celulite e a erisipela } \\
\text { fazem parte do mesmo }\end{array}$ & $\begin{array}{l}\text { Ambas as infecções são } \\
\text { comuns e apresentam }\end{array}$ \\
\hline
\end{tabular}




\begin{tabular}{|c|c|c|c|c|c|c|}
\hline $\begin{array}{l}\text { management of } \\
\text { cellulitis and } \\
\text { erysipelas }^{(3)}\end{array}$ & $\begin{array}{l}\text { Hospital } \\
\text { Medicine }\end{array}$ & 2015 & $\begin{array}{l}\text { manejo e a } \\
\text { prevenção } \\
\text { celulite/erisipela. }\end{array}$ & literatura & $\begin{array}{l}\text { processo patológico. O } \\
\text { diagnóstico dessas } \\
\text { doenças é clínico, e o } \\
\text { tratamento é com } \\
\text { antimicrobianos, } \\
\text { levando-se } \\
\text { consideração as diretrizes } \\
\text { locais, conforme os } \\
\text { padrões regionais de } \\
\text { resistência bacteriana. }\end{array}$ & $\begin{array}{l}\text { altas taxas de recidivas } \\
\text { pelo fato de não haver } \\
\text { um diagnóstico preciso } \\
\text { e ensaios clínicos da } \\
\text { maneira correta para } \\
\text { utilizar } \\
\text { antimicrobianos } \\
\text { disponíveis. }\end{array}$ \\
\hline $\begin{array}{l}\text { 5. Abordagem e } \\
\text { reflexões para o } \\
\text { cuidado do } \\
\text { cliente com } \\
\text { erisipela }\end{array}$ & $\begin{array}{l}\text { Revista } \\
\text { Brasileira } \\
\text { de } \\
\text { Educação e } \\
\text { Saúde }\end{array}$ & $\begin{array}{l}\text { Medline/ } \\
2016\end{array}$ & $\begin{array}{l}\text { Realizar uma análise } \\
\text { sobre os cuidados } \\
\text { específicos prestados } \\
\text { a clientes com } \\
\text { erisipela, a fim de } \\
\text { contribuir com o }\end{array}$ & $\begin{array}{l}\text { Revisão } \\
\text { integrativa }\end{array}$ & $\begin{array}{l}\text { A erisipela é considerada } \\
\text { uma infecção cutânea; } \\
\text { sua etiologia é } \\
\text { estreptocócica; apresenta } \\
\text { recidivas frequentes. A } \\
\text { utilização de métodos }\end{array}$ & $\begin{array}{l}\text { A Enfermagem, por } \\
\text { meio da Sistematização } \\
\text { da Assistência de } \\
\text { Enfermagem, é capaz de } \\
\text { promover um cuidado } \\
\text { integral e humanizado }\end{array}$ \\
\hline
\end{tabular}




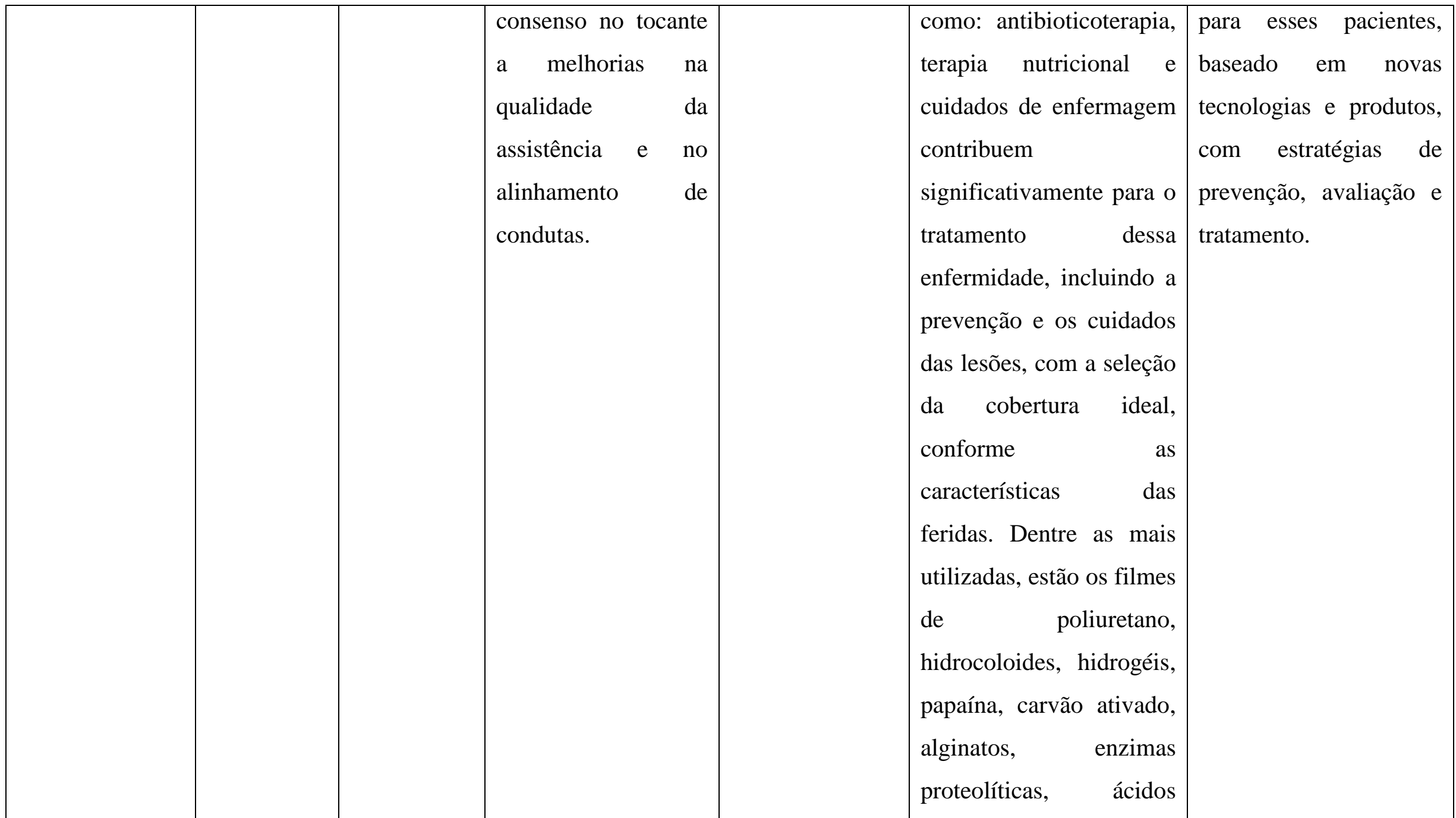




\begin{tabular}{|c|c|c|c|c|c|c|}
\hline & & & & & $\begin{array}{l}\text { graxos essenciais e } \\
\text { derivados de prata. }\end{array}$ & \\
\hline $\begin{array}{l}\text { 6. Clinical } \\
\text { mimics: an } \\
\text { emergency } \\
\text { medicine- } \\
\text { focused review } \\
\text { of } \\
\text { cellulitis }^{\text {mimics }}\end{array}$ & $\begin{array}{l}\text { The Journal } \\
\text { of } \\
\text { Emergency } \\
\text { Medicine }\end{array}$ & $\begin{array}{l}\text { Pubmed/ } \\
2017\end{array}$ & $\begin{array}{l}\text { Investigar os sinais e } \\
\text { os sintomas da } \\
\text { celulite e uma } \\
\text { abordagem sobre o } \\
\text { tratamento da } \\
\text { celulite e infecções } \\
\text { que se assemelham a } \\
\text { ela. }\end{array}$ & $\begin{array}{l}\text { Revisão de } \\
\text { literatura }\end{array}$ & $\begin{array}{l}\text { A definição de celulite } \\
\text { inclui eritema, } \\
\text { endurecimento calor e } \\
\text { edema, o que a confunde } \\
\text { com outras enfermidades. } \\
\text { Essas condições incluem } \\
\text { sepse } \\
\text { bursite, articulação } \\
\text { séptica, trombose venosa } \\
\text { profunda, necrotizante, } \\
\text { fasciíte a a artrite } \\
\text { tenossinovite flexora, } \\
\text { celulite orbital, síndrome } \\
\text { do choque tóxico, } \\
\text { erisipela, abscesso, } \\
\text { paronía }\end{array}$ & $\begin{array}{l}\text { A celulite apresenta-se } \\
\text { de forma semelhante a } \\
\text { outras enfermidades } \\
\text { decorrentes } \\
\text { inflamação da pele. A } \\
\text { duração e a localização } \\
\text { são de extrema } \\
\text { relevância } \\
\text { confirmar o diagnóstico } \\
\text { preciso. }\end{array}$ \\
\hline
\end{tabular}




\begin{tabular}{|c|c|c|c|c|c|c|}
\hline & & & & & $\begin{array}{l}\text { gotosa. O diagnóstico é } \\
\text { difícil e deve ser } \\
\text { realizado com base em } \\
\text { uma história clínica e } \\
\text { exame físico completo } \\
\text { com a finalidade de } \\
\text { identificar corretamente } \\
\text { o tipo de doença e sua } \\
\text { etiologia. }\end{array}$ & \\
\hline $\begin{array}{l}\text { 7.Clinical } \\
\text { Guidelines for } \\
\text { the antibiotic } \\
\text { treatment for } \\
\text { community- } \\
\text { acquired skin } \\
\text { and soft tissue } \\
\text { infection }\end{array}$ & $\begin{array}{l}\text { Infect } \\
\text { Chemother }\end{array}$ & $\begin{array}{l}\text { Scopus/ } \\
2017\end{array}$ & $\begin{array}{l}\text { Fazer } \\
\text { recomendações para } \\
\text { o diagnóstico e o } \\
\text { manejo de infecção } \\
\text { da pele e dos tecidos } \\
\text { moles, dentre eles, } \\
\text { impetigo/eczema, } \\
\text { infecção purulenta } \\
\text { da pele e partes } \\
\text { moles, erisipela e }\end{array}$ & $\begin{array}{l}\text { Revisão } \\
\text { sistemática }\end{array}$ & $\begin{array}{l}\text { A erisipela é uma } \\
\text { infecção das partes } \\
\text { moles, que se infiltra na } \\
\text { parte superior da derme, } \\
\text { e a celulite atinge a } \\
\text { camada subcutânea. A } \\
\text { cultura de sangue ou } \\
\text { biópsia por punção não é } \\
\text { recomendada para o } \\
\text { diagnóstico dessas }\end{array}$ & $\begin{array}{l}\text { A erisipela e a celulite } \\
\text { são infecções distintas } \\
\text { que causam sinais e } \\
\text { sintomas, muitas vezes, } \\
\text { parecidos, o que } \\
\text { dificulta o diagnóstico. } \\
\text { A cultura de sangue e a } \\
\text { biópsia não são } \\
\text { recomendadas, exceto } \\
\text { em alguns casos. Indica- }\end{array}$ \\
\hline
\end{tabular}




\begin{tabular}{|c|c|c|c|c|c|c|}
\hline & & & $\begin{array}{l}\text { celulite, fasciíte } \\
\text { necrosante, } \\
\text { piomiosite, } \\
\text { mionecrose } \\
\text { clostridiana } \\
\text { mordida de animal. }\end{array}$ & & $\begin{array}{l}\text { doenças, mas pode ser } \\
\text { útil na identificação do } \\
\text { patógeno em pacientes } \\
\text { imunossuprimidos, com } \\
\text { neutropenia, lesão por } \\
\text { pressão ou acometidos } \\
\text { por mordida de animal. }\end{array}$ & $\begin{array}{l}\text { se antibioticoterapia } \\
\text { para tratar essas } \\
\text { infecções. }\end{array}$ \\
\hline $\begin{array}{l}\text { 8. Actualización } \\
\text { en el abordaje y } \\
\text { manejo de }^{\text {celulites }^{(14)}}\end{array}$ & $\begin{array}{l}\text { Actas } \\
\text { Dermosifili } \\
\text { ogr }\end{array}$ & BVS/ 2019 & $\begin{array}{l}\text { Apresentar } \\
\text { atualizações sobre } \\
\text { manifestações } \\
\text { clínicas, fatores } \\
\text { predisponentes, } \\
\text { microbiologia, } \\
\text { diagnóstico, } \\
\text { tratamento } \\
\text { complicações sobre } \\
\text { celulite e erisipela. }\end{array}$ & $\begin{array}{l}\text { Revisão de } \\
\text { literatura }\end{array}$ & $\begin{array}{l}\text { A erisipela e a celulite } \\
\text { são doenças que } \\
\text { apresentam } \\
\text { comprometimento da } \\
\text { pele em estágios } \\
\text { diferentes. } \\
\text { O diagnóstico é baseado } \\
\text { nas manifestações } \\
\text { clínicas, e o tratamento } \\
\text { com antibióticos, por via } \\
\text { oral ou parenteral, a } \\
\text { depender do grau de }\end{array}$ & $\begin{array}{l}\text { É de extrema } \\
\text { importância reconhecer } \\
\text { as manifestações e os } \\
\text { fatores predisponentes à } \\
\text { celulite e à erisipela, } \\
\text { tratar as possíveis portas } \\
\text { de entrada, como } \\
\text { micose interdigital, e } \\
\text { conhecer as formas de } \\
\text { tratamento adequadas. }\end{array}$ \\
\hline
\end{tabular}




\begin{tabular}{|c|c|c|c|c|c|c|}
\hline & & & & & $\begin{array}{l}\text { comprometimento, } \\
\text { conforme a classificação } \\
\text { de Eron. As principais } \\
\text { complicações são edema, } \\
\text { úlceras venosas e fasciíte } \\
\text { necrotizante. }\end{array}$ & \\
\hline $\begin{array}{l}\text { 9. Colonization } \\
\text { of } \beta \text {-hemolytic } \\
\text { streptococci in } \\
\text { patients } \\
\text { with } \\
\text { erysipelas-a } \\
\text { prospective } \\
\text { study }\end{array}$ & $\begin{array}{l}\text { Eur J Clin } \\
\text { Microbiol } \\
\text { Infect Dis }\end{array}$ & BVS, 2019 & $\begin{array}{l}\text { Investigar se a } \\
\text { amostragem } \\
\text { bacteriológica } \\
\text { perianal pode } \\
\text { representar uma } \\
\text { nova ferramenta para } \\
\text { o diagnóstico da } \\
\text { erisipela. }\end{array}$ & $\begin{array}{l}\text { Estudo de } \\
\text { coorte, } \\
\text { prospectivo }\end{array}$ & $\begin{array}{l}\text { Foram incluídos } 50 \\
\text { pacientes, } 25 \text { com } \\
\text { erisipela e } 25 \text { controles } \\
\text { com febre. No grupo com } \\
\text { erisipela, } 11 \text { pacientes } \\
\text { (44\%) } \\
\text { colonizados } \text { com } \\
\text { estreptococos } \\
\text { hemolíticos } \\
\text { sendo que dez deles } \\
\text { estavam colonizados na } \\
\text { região perianal, e um, na } \\
\text { orofaringe. Apenas um }\end{array}$ & $\begin{array}{l}\text { Evidenciou-se uma } \\
\text { colonização perianal } \\
\text { pelos SHB em pacientes } \\
\text { com erisipela em } \\
\text { comparação febre } \\
\text { pacientes com outras } \\
\text { causada por aponta as } \\
\text { condições e a promo } \\
\text { culturas perianais comora } \\
\text { uma forma promissora } \\
\text { de diagnosticar casos de } \\
\text { erisipela. }\end{array}$ \\
\hline
\end{tabular}




\begin{tabular}{|l|l|l|l|l|}
\hline & & & &
\end{tabular} \mid $\begin{aligned} & \text { paciente no grupo } \\
& \text { controle estava } \\
& \text { colonizado. Todos os } \\
& \text { pacientes com erisipela } \\
& \text { colonizados com os SHB } \\
& \text { apresentaram eritema } \\
& \text { localizado no membro } \\
& \text { inferior. A Streptococcus } \\
& \text { dysgalactiae coloniza a } \\
& \text { região perianal em uma } \\
& \text { proporção substancial de } \\
& \text { pacientes com erisipela. }\end{aligned}$

Fonte: Elaborado pelos autores, 2020.

Os artigos são unânimes quanto ao uso de antimicrobianos para o tratamento, e a penicilina e seus derivados são as drogas mais indicadas; em seguida, vem a clindamicina ou eritromicina, como alternativa para pacientes alérgicos às penicilinas. $\mathrm{O}$ tratamento com antibióticos orais é indicado para as infecções leves, e nas infecções moderadas e graves, recomendam-se usar os antibióticos injetáveis. Essas informações estão no Quadro 2. 
Quadro 2 - Fármacos indicados pelos artigos pesquisados. 2020.

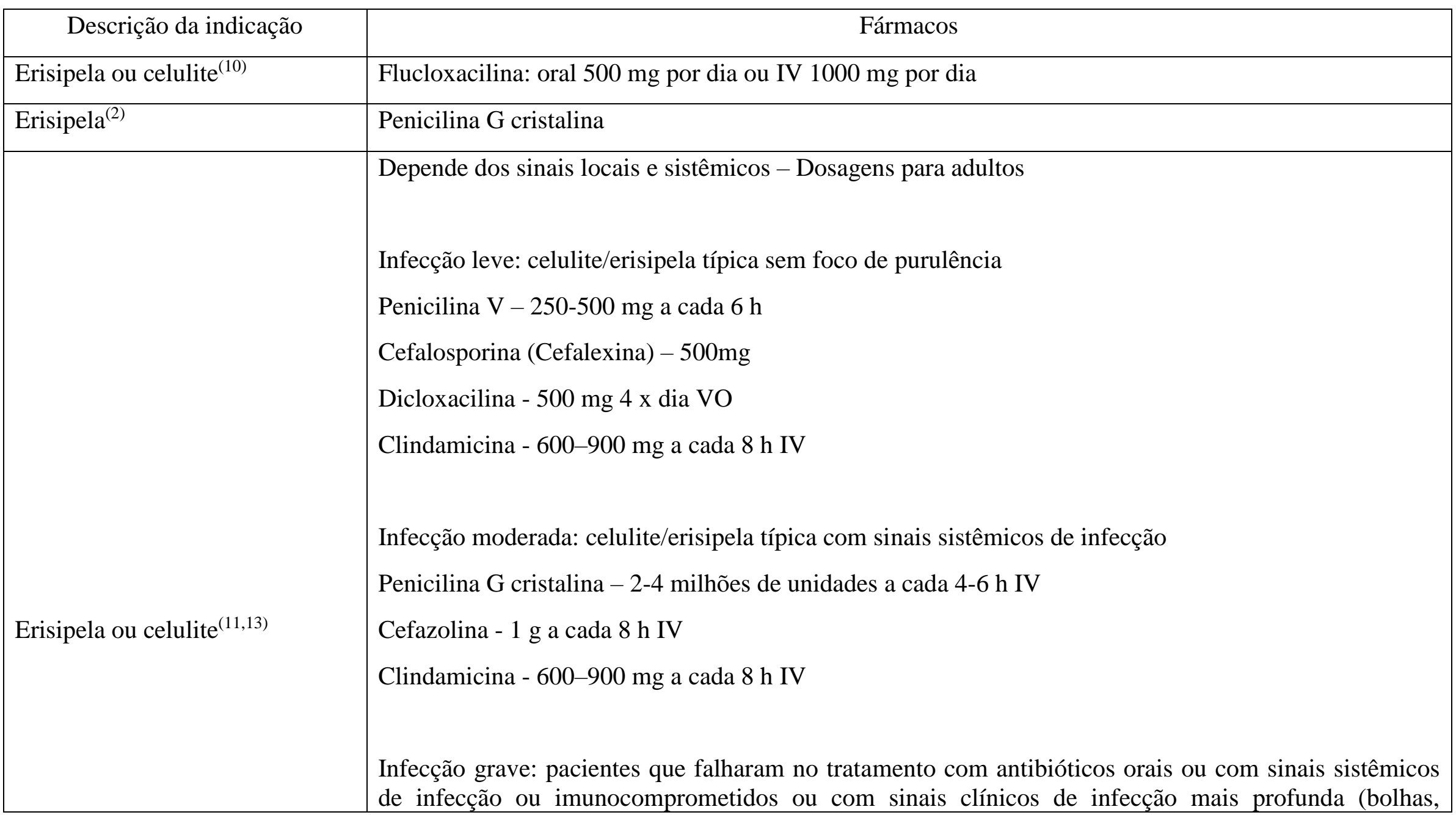




\begin{tabular}{|c|c|}
\hline & 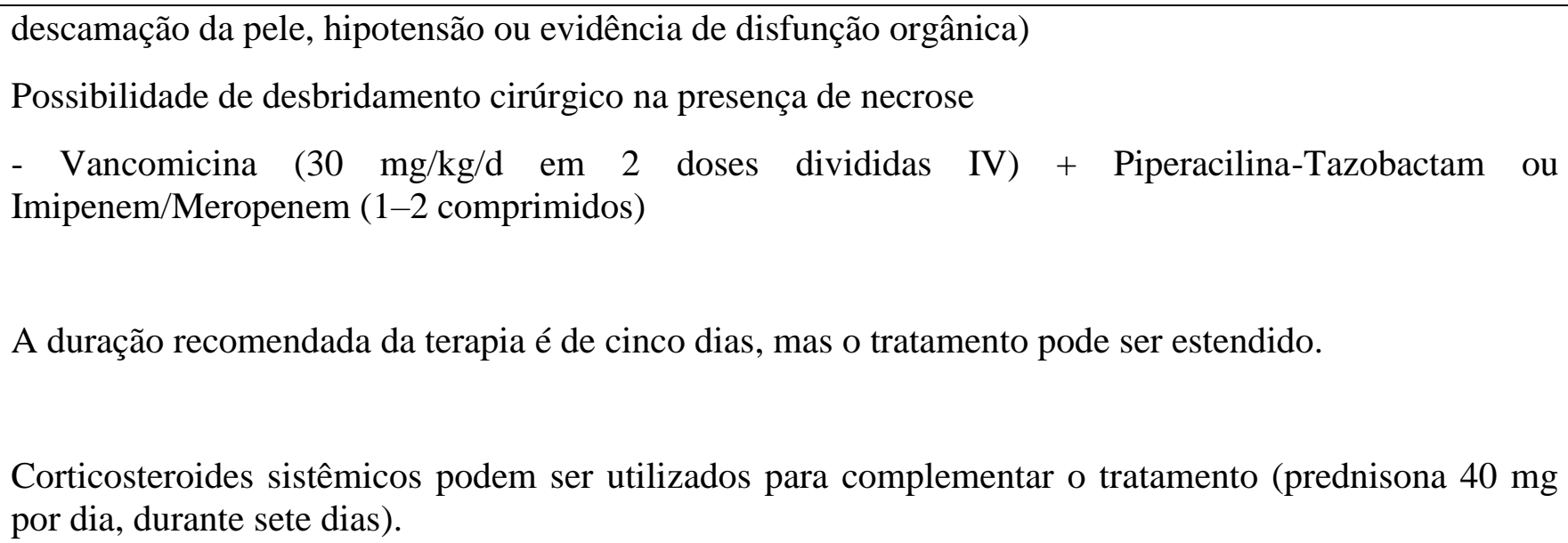 \\
\hline Erisipela ou Celulite $^{(14)}$ & $\begin{array}{l}\text { Ibuprofeno } 400 \mathrm{mg} \text { a cada } 6 \text { horas por } 5 \text { dia, associado a antibióticos OU } \\
\text { Corticosteroides: adição de prednisolona por } 8 \text { dias ao tratamento com penicilina }\end{array}$ \\
\hline $\begin{array}{l}\text { Erisipela ou Celulite }^{(11,13)} \\
\text { Staphylococcus aureus sensível à } \\
\text { meticilina (MSSA) }\end{array}$ & $\begin{array}{l}\text { Oxacilina - } 1-2 \text { g a cada } 4 \text { h IV } \\
\text { Cefazolina - } 1 \text { g a cada } 8 \text { h IV } \\
\text { Clindamicina - } 600 \mathrm{mg} \text { a cada } 8 \text { h IV ou } 300-450 \mathrm{mg} 4 \text { x dia VO } \\
\text { Dicloxacilina - } 500 \mathrm{mg} 4 \mathrm{x} \text { dia VO } \\
\text { Cefalexina - } 500 \mathrm{mg} 4 \text { x dia VO } \\
\text { Doxiciclina, minociclina - } 100 \mathrm{mg} 2 \mathrm{x} \text { dia VO } \\
\text { Trimetoprim-sulfametoxazol - } 1-2 \text { comprimidos VO }\end{array}$ \\
\hline $\begin{array}{l}\text { Erisipela ou celulite }{ }^{(11,13)} \\
\text { Staphylococcus aureus resistente }\end{array}$ & Vancomicina (30 mg/kg/d em 2 doses divididas IV) \\
\hline
\end{tabular}




\begin{tabular}{|c|c|}
\hline à meticilina (MRSA) & $\begin{array}{l}\text { Linezolida - } 600 \mathrm{mg} \text { a cada } 12 \mathrm{~h} \text { IV ou } 600 \mathrm{mg} 2 \mathrm{x} \text { dia VO } \\
\text { Clindamicina - } 600 \mathrm{mg} \text { a cada } 8 \mathrm{~h} \text { IV ou } 300-450 \mathrm{mg} 2 \mathrm{x} \text { dia VO } \\
\text { Doxiciclina, minociclina - } 100 \mathrm{mg} 2 \mathrm{x} \text { dia VO } \\
\text { Trimetoprim-sulfametoxazol - } 1-2 \text { comprimidos VO }\end{array}$ \\
\hline $\begin{array}{l}\text { Erisipela ou celulite causada por } \\
\text { Staphylococcus aureus resistente } \\
\text { à meticilina (MRSA) }\end{array}$ & Glicopeptideos (como o teicoplanina), linezolida ou clindamicina \\
\hline $\begin{array}{l}\text { Erisipela ou Celulite com } \\
\text { infecções graves, sem sucesso } \\
\text { com outros medicamentos }^{(3)}\end{array}$ & Tetraciclinas, ou associação de rifampicina e glicopeptídeo com ácido fusídico. \\
\hline $\begin{array}{l}\text { Erisipela ou Celulite em } \\
\text { pacientes alérgicos à } \\
\text { penicilina }^{(14,15)}\end{array}$ & Eritromicina ou clindamicina \\
\hline $\begin{array}{l}\text { Celulite não purulenta (excluir } \\
\text { MRSA) }^{(14)}\end{array}$ & $\begin{array}{l}\text { A duração da terapia deve ser individualizada. Geralmente, são recomendados cinco dias para pacientes } \\
\text { com celulite não complicada e até } 14 \text { dias em infecções graves ou de resposta lenta. } \\
\text { Oral } \\
\text { Dicloxacilina- } 500 \mathrm{mg} / 6 \mathrm{~h} \\
\text { Cefadroxil - } 500 \mathrm{mg} / 12 \mathrm{~h} \\
\text { Clindamicina }-300-450 \mathrm{mg} / 6-8 \mathrm{~h}\end{array}$ \\
\hline
\end{tabular}




\begin{tabular}{|c|c|}
\hline & $\begin{array}{l}\text { Parenteral } \\
\text { Cefazolina- } 1-2 \mathrm{~g} / 8 \mathrm{~h} \\
\text { Oxacilina - } 2 \mathrm{~g} / 4 \mathrm{~h} \\
\text { Clindamicina - } 600-900 \mathrm{mg} \text { a cada } 8 \text { horas } \\
\text { Nafcilina - } 2 \mathrm{~g} / 4 \mathrm{~h}\end{array}$ \\
\hline $\begin{array}{l}\text { Celulite não purulenta por } \\
\text { estreptococo beta-hemolítico + } \\
\text { MRSA }^{(14)}\end{array}$ & $\begin{array}{l}\text { Clindamicina - 300-450mg VO a cada } 8 \mathrm{~h} \\
\text { Amoxicilina 500mg VO a cada } 8 \mathrm{~h}+\text { Trimetoprim / sulfametoxazol } 160 \mathrm{mg} / 800 \mathrm{mg} / 12 \mathrm{~h} \text { (forte) } \\
\text { Amoxicilina } 500 \mathrm{mg} \text { VO a cada } 8 \mathrm{~h}+\text { Doxiciclina } 100 \mathrm{mg} \text { por VO a cada } 12 \mathrm{~h} \\
\text { Amoxicilina } 500 \mathrm{mg} \text { VO a cada } 8 \mathrm{~h}+\text { Minociclina } 200 \mathrm{mg} \text { por dia, depois } 100 \mathrm{mg} \text { por via oral a cada } 12 \\
\mathrm{~h} \\
\text { Linezolida } 600 \mathrm{mg} \text { VO a cada } 12 \mathrm{~h} \\
\text { Tedizolida } 200 \mathrm{mg} \text { por dia VO }\end{array}$ \\
\hline Celulite purulenta por $\mathrm{MRSA}^{(14)}$ & $\begin{array}{l}\text { Oral } \\
\text { Clindamicina 300-450mg 3-4 vezes ao dia } \\
\text { Trimetoprim / sulfametoxazol 160-320 mg / 800-1.600mg duas vezes ao dia (forte) } \\
\text { Doxiciclina } 100 \mathrm{mg} 2 \text { vezes ao dia } \\
\text { Minociclina } 200 \mathrm{mg} \text { por dia e depois } 100 \mathrm{mg} 2 \text { vezes ao dia } \\
\text { Linezolida } 600 \mathrm{mg} 2 \text { vezes ao dia } \\
\text { Parenteral }\end{array}$ \\
\hline
\end{tabular}




\begin{tabular}{|l|l|}
\hline & $\begin{array}{l}\text { Vancomicina } 15-20 \mathrm{mg} / \mathrm{kg} \text { a cada } 8-12 \mathrm{~h} \text { (máximo de } 2 \mathrm{~g} / \mathrm{dose}) \\
\text { Daptomicina } 4 \mathrm{mg} / \mathrm{kg} 1 \mathrm{vez} \text { ao dia; se bacteremia: } 6 \mathrm{mg} / \mathrm{kg} \text { uma vez ao dia } \\
\text { Linezolida } 600 \mathrm{mg} 2 \text { vezes ao dia. }\end{array}$ \\
\hline Erisipela $^{(14)}$ & $\begin{array}{l}\text { Oral } \\
\text { Penicilina V } 500 \mathrm{mg} / 6 \mathrm{~h} \\
\text { Amoxicilina } 500 \mathrm{mg} \text { a cada } 8 \text { horas } \\
\text { Eritromicina } 250 \mathrm{mg} / 6 \mathrm{~h}\end{array}$ \\
$\begin{array}{l}\text { Parenteral } \\
\text { Ceftriaxona } 1 \mathrm{~g} \mathrm{por} \mathrm{dia} \\
\text { Cefazolina } 1-2 \mathrm{~g} / 8 \mathrm{~h}\end{array}$ \\
\hline
\end{tabular}

Fonte: Elaborado pelos autores, 2020. 


\section{DISCUSSÃO}

\section{Diagnóstico}

O diagnóstico diferencial de ambas as enfermidades é difícil porque suas manifestações clínicas são semelhantes $^{(9,10,15,14)}$.

Quatro estudos ${ }^{(3,11,12,13)}$ são enfáticos quanto à necessidade de exame físico minucioso, com análise dos sinais e sintomas específicos, já que, nem sempre, os exames laboratoriais e de imagem auxiliam o diagnóstico.

A erisipela causa rash cutâneo, com placa eritematosa elevada, firme e bem definida e aumento da temperatura local e é dolorosa à palpação ${ }^{(3,14)}$. Quando esses sinais acometem a orelha, são conhecidos como Sinal de Milian, que é específico para a erisipela, já que, nesse local, não há derme profunda $^{(3)}$. Por outro lado, a celulite causa um rash cutâneo rosado, com bordas mal definidas, quente e sensível e que pode, algumas vezes, ter aspecto de casca de laranja, com danos linfáticos permanentes. Uma minoria desenvolve sepse grave, gangrena local ou fasciíte necrotizante ${ }^{(3,14)}$. Assim, os profissionais devem observar atentamente essas manifestações clínicas.

Alguns exames laboratoriais podem ser realizados de forma complementar, como exame de sangue, com observação da leucocitose e elevação de proteína C-reativa. Contudo, os marcadores bioquímicos normais não excluem as doenças ${ }^{(3)}$.
Já outros estudos ${ }^{(3,12,13)}$ referem que exames como os de hemocultura, cultura por aspiração ou biópsia por punção não são eficazes no diagnóstico, porque não identificam as bactérias causadoras dessas doenças. No entanto, podem ser úteis em casos específicos, como os de pacientes imunossuprimidos, em tratamento contra o câncer, neutropênicos, queimados ou com mordidas por animais ${ }^{(11,13)}$. Contudo, outro estudo da amostra orienta que a hemocultura pode ser importante para nortear a conduta terapêutica, principalmente em casos de sepse, e a cultura de aspirados de bolhas deve ser feita sempre que possível ${ }^{(3)}$.

Pesquisa afirma que o linfedema compromete os sistemas de filtragem bacteriana e possibilita o acesso de bactérias no tecido mole à circulação sistêmica e que a especificação microbiológica, seja por hemocultura ou swab da lesão, é útil, quando positiva, para orientar a antibioticoterapia ${ }^{(16)}$. Outra investigação comparou a técnica de coleta da cultura do swab (pela técnica de Levine) com a biópsia, e os resultados foram semelhantes, com concordância de 87,2 a $97,8 \%{ }^{(17)}$. Nesse sentido, percebe-se que a técnica da coleta é importante, e a cultura pode auxiliar a terapêutica, mas depende do protocolo da instituição sobre a necessidade desses exames.

Além do exame físico completo e detalhado da celulite, deve-se suspeitar de que a inflamação se estenda pelas articulações. É 
necessário fazer exames de imagem, como ultrassom, radiografia ou tomografia computadorizada para diferenciá-la de outras doenças semelhantes, como a erisipela ${ }^{(12-13)}$.

Os autores concordam que o exame é mais clínico e que os exames laboratoriais ou de imagem só devem ser solicitados em casos específicos, como para pacientes com baixa imunidade ou com suspeita de inflamação nas articulações. Portanto, não há exame específico para distinguir as duas enfermidades.

\section{Tratamento}

Segundo os artigos, o tratamento depende do grau de severidade da doença, da localização e das comorbidades do paciente ${ }^{(3,}$ 11, 13, 14). Geralmente, os antimicrobianos orais são os preferidos para o tratamento de erisipela e de celulite, quando o paciente estiver com temperatura $<37,8^{\circ}$ por 48 horas e marcadores bioquímicos de infecção reduzidos. O tratamento dura, geralmente, de uma a duas semanas, mas o julgamento clínico deve ser utilizado caso seja necessário interrompê-lo ${ }^{(3)}$. Os sintomas sistêmicos são temperatura $>38^{\circ} \mathrm{C}$, taquicardia $(>90 \mathrm{bpm})$, taquipneia (> 20 irpm) ou $\mathrm{PaCO}_{2}<$ $32 \mathrm{mmHg}^{(11)}$.

A droga escolhida citada pela maior parte dos artigos é a penicilina e seus derivados, já que a maioria dos casos de erisipela é causada pelo $S$. pyogenes, que é sensível a esse antimicrobiano. Esse fármaco interfere na última etapa da síntese da parede bacteriana, o que causa uma membrana instável, com lise pela pressão osmótica ou pela ativação de autolisinas ${ }^{(18)}$. Contudo, deve-se observar que a celulite pode ser causada pelos estreptococos $\beta$-hemolíticos, como o $S$. pyogenes, ou pelo MRSA ou $S$. aureus resistente à oxacilina. Nesses casos, o tipo de microrganismo envolvido, a profundidade e a extensão da lesão, com progressão rápida, requerem o uso do sulfametoxazol-trimetoprim ou clindamicina $^{(19)}$. A indicação da penicilina $G$ cristalina, quando não há cultura do patógeno, requer uma avaliação constante, a fim de identificar precocemente se a terapêutica não está sendo eficaz.

A penicilina natural é obtida a partir de fermentações do fungo Penicillium chrysogenum, que são a Benzilpenicilina (penicilina $\mathrm{G}$ cristalina, penicilina $\mathrm{G}$ procaína e penicilina $G$ benzantina) e a Fenoximetilpenicilina (penicilina V). Contudo, há vários tipos de penicilina desenvolvidos a partir da estrutura básica das naturais, para serem resistentes às $\beta$ lactamases, enzimas produzidas pelas bactérias resistentes. Dentre as citadas pelos artigos como semissintéticas, estão a dicloxacilina, a amoxicilina e a flucloxacilina.

Para os pacientes com alergia à penicilina, os estudos indicam eritromicina ou clindamicina $^{(14,15)}$. A eritromicina é um antibiótico do grupo dos macrolídeos, que 
inibe a síntese proteica $^{(20)}$, e a clindamicina, que é do grupo das lincosamidas, também tem o mesmo local de ação da eritromicina, que é a subunidade 50S do ribossoma bacteriano, e deve ser evitada por pacientes com disfunção hepática ou renal ${ }^{(20)}$.

Assim, de um modo geral, a resposta terapêutica deve ser avaliada a cada 48 horas, monitorando-se os marcadores inflamatórios e descartando a presença de abscessos ${ }^{(11)}$. A celulite começa dois a três dias depois da infecção e, normalmente, é resolvida dentro de 24 a 48 horas depois do início dos antibióticos $^{(12)}$.

\section{Cuidados gerais}

Além do tratamento farmacológico, a participação da equipe de enfermagem é de extrema importância, porque o cuidado com a pele requer mais de uma intervenção avançada, baseada numa abordagem holística $^{(2)}$.

Nessa perspectiva, várias medidas são adotadas por esses profissionais para o tratamento, como: elevar os MMII, especialmente na fase inicial - pode ser necessário enfaixar a perna para diminuir o edema (Figura 2); manter a pele hidratada ${ }^{(9,14)}$; tratar as lesões dérmicas; higienizar a pele; administrar medicamentos prescritos; monitorar e proteger a pele quanto aos sinais de lesões por pressão; mudar de decúbito a cada duas horas e instruir o paciente e a família sobre os cuidados com a ferida $^{(9)}$.

Figura 2 - Compressão elástica aplicada no membro afetado desde os artelhos Arquivo dos autores - Paraíba, Brasil. 2017.

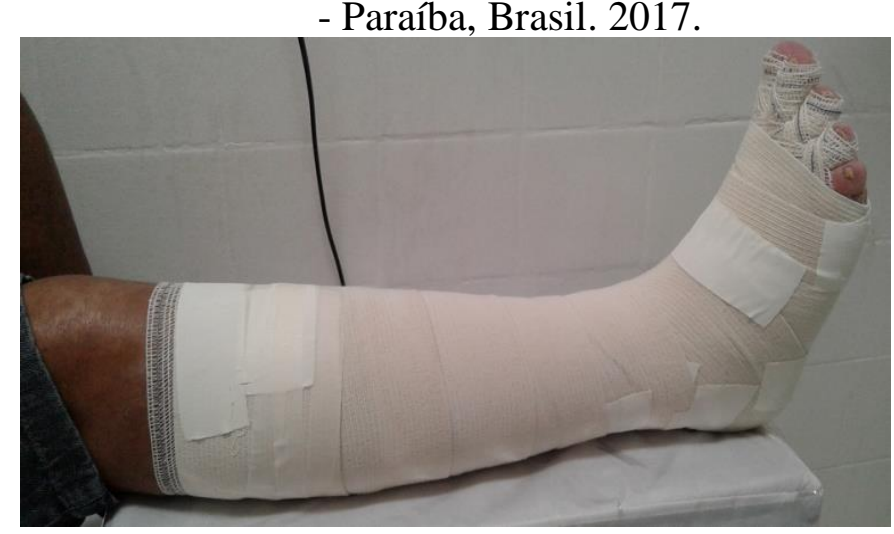

Fonte: Arquivos dos autores, 2017.

Os artigos não apresentaram detalhes sobre as orientações de cuidados com a pele e com as lesões. Outros autores orientam que, se não houver ruptura da pele, a hidratação pode ser mantida com ácidos graxos essenciais (AGE). Se surgirem bolhas ou 
tecidos necróticos superficiais, deve-se remover o tecido frouxo com esfregaço com gaze e solução fisiológica, e as lesões devem ser ocluídas com coberturas conforme as características da ferida $^{(21)}$.

Quando a necrose não se estabeleceu macroscopicamente, indica-se o uso de coberturas secas até que isso aconteça e, depois, algum agente desbridante ${ }^{(21)}$.

Nada foi encontrado na literatura acerca do uso de compressas geladas para aliviar a dor, experiência exitosa pelos autores desta pesquisa e outros profissionais.

\section{CONSIDERAÇÕES FINAIS}

O diagnóstico é basicamente clínico e não se pode diferenciar erisipela de celulite, já que as manifestações clínicas são semelhantes e não se indicam exames laboratoriais ou de imagem rotineiros. Isso só é feito nos casos mais complicados.

No tratamento dessas doenças, utilizam-se os mesmos antibióticos, o que diminui o problema anterior de confirmar o diagnóstico, porque a droga citada pela maioria dos artigos, para ambas as infecções, é a penicilina e seus derivados, com algumas variações quanto ao tempo de tratamento. Os cuidados gerais incluem hidratação e nutrição adequadas, redução do edema e cicatrização das lesões de pele, o que é papel fundamental da equipe de enfermagem.

Este estudo apresenta limitações devido à escassez de publicações sobre o tema e de artigos secundários como amostra. Assim, são necessários mais estudos originais para que se possa fazer um levantamento das evidências e contribuir para que essas infecções sejam manejadas corretamente.

\section{REFERÊNCIAS}

1. Dalal A, Eskin-Schwartz M, Mimouni DRS, Days W, Hodak E, Leibovici L, et al. Interventions for the prevention of recurrent erysipelas and cellulite (review). Cochrane Database of Systematic Reviews [Internet]. 2017 [acesso em 05 abr 2020]; 1-60. Disponível em: https://www.ncbi.nlm.nih.gov/pmc/articles/P MC6481501/pdf/CD009758.pdf

2. Cruz RAO, Miranda EG, Santos EC, Ferreira MGMS, SANTANA R A. Abordagem e reflexões para o cuidado do cliente com erisipela. Rebes [Internet]. 2016 [acesso em 05 abr 2020]; 6(1):22-6. Disponível em: https://www.gvaa.com.br/revista/index.php/R EBES/article/view/3902/3625

3. Maxwell-Scott, Kandil H. Diagnosis and management of cellulitis and erysipelas. $\mathrm{Br} \mathbf{J}$ Hosp Med [Internet]. 2015 [acesso em 05 abr 2020]; 76(8):114-7. Disponível em: https://scihub.tw/10.12968/hmed.2015.76.8.C114.

4. Linke $\mathrm{M}$, Booken N. Risk factors associated with a reduced response in the treatment of erysipelas. J Dtsch Dermatol Ges [Internet]. 2015 [acesso em 05 abr 2020]; 13(3):217-25. Disponível em: https://scihub.se/https://doi.org/10.1111/ddg.12575

5. Kozłowska D, Myśliwiec H, Kiluk $P$, Baran A, Milewska AJ, Flisiak I. Clinical and epidemiological assessement of patients hospitalized for primary and recurrent erysipelas. Przegl Epidemiol [Internet]. 2016 [acesso em 05 abr 2020]; 70(4):575-84. 
Disponível

em:

file:///C:/Users/Arthur/Downloads/PE_nr_4_2 $\underline{016 \text { art } 6 . p d f}$

6. Raff AB, Kroshinsky, D. Cellulitis: a review. JAMA [Internet]. 2016 [acesso em 05 abr 2020]; 316(3):325-37. Diponível em: https://sci-hub.se/10.1001/jama.2016.8825

7. Perelló-Alzamora MR, Santos-Duran JC, Sánchez-Barba $\mathrm{H}$, Cañueto $\mathrm{J}$, Marcos $\mathrm{H}$, Unamuno P. Clinical and epidemiological characteristics of adult patients hospitalized for erysipelas and cellulitis. Eur J Clin Microbiol Infect Dis [Internet]. 2012 [acesso em 05 abr 2020]; 31(9):2147-52. Disponível em: https://sci-hub.tw/10.1007/s10096-0121549-2.

8. Sousa LMM, Firmino CF, Marques-Vieira CMA, Severino SSP, Pestana HCFC. Revisões da literatura científica: tipos, métodos e aplicações em Enfermagem. REPER [Internet]. 2018 [acesso em 05 abr 2020]; 1(1):45-54. Disponível em: http://dspace.uevora.pt/rdpc/bitstream/10174/ 25938/1/rperv1n1\%2cp.45-54.pdf

9. Silva PLN, Abreu GGD, Fonseca JR, Souto SGT, Gonçalves RPF. Diagnóstico e intervenções de enfermagem em paciente com erisipela: estudo de caso em Hospital de Ensino. Revista Eletrônica Gestão e Saúde [Internet]. 2013 [acesso em 05 abr 2020]; 4(4):1512-516. Disponível em: https://periodicos.unb.br/index.php/rgs/article/ view/399/385

10. Cranendonck DR, Opmeer BC, Prins JM, Wiersinga WJ. Comparing short to standard duration of antibiotic therapy for patients hospitalized with cellulitis (DANCE): study protocol for a randomized controlled trial. BMC Infectious Diseases [Internet]. 2014 [acesso em 05 abr 2020]; 14:235. Disponível em:

https://www.ncbi.nlm.nih.gov/pmc/articles/P MC4016641/pdf/1471-2334-14-235.pdf
11. Stevens DL, Bisno AL, Chambers HF, Dellinger EP, Goldstein EJC, Gorbach SL et al. Practice guidelines for the diagnosis and management of skin and soft tissue infections: 2014 - Update by the infectious diseases society of America. Clinical Infectious Diseases [Internet]. 2014 [acesso em 05 abr 2020]; 59:147-59. Disponível em: https://www.ncbi.nlm.nih.gov/pubmed/24973 422

12. Blumberg G, Longo B, Koyfman A. Clinical mimics: an emergency medicinefocused review of cellulitis mimics. $\mathrm{O}$ jornal of Emergency Medicine [Internet]. 2017 [acesso em 05 abr 2020]; 53(4):475-84. Disponível em: https://www.scihub.tw/10.1016/j.jemermed.2017.06.002

13. Kwark YG, Choi S, Kim T, Park SY, Seo $\mathrm{SH}$, Kim MB, et al. Clinical Guidelines for the Antibiotic Treatment for CommunityAcquired Skin and Soft Tissue Infection. Infect Chemother [Internet]. 2017 [acesso em 05 abr 2020]; 49(4):301-25. Disponível em: https://www.ncbi.nlm.nih.gov/pmc/articles/P MC5754343/pdf/ic-49-301.pdf

14. Ortiz-Lazo E, Arriagada-Egnen C, Poehls C, Concha-Rogazy M. Actualización en el abordaje y manejo de celulites. Actas Dermosifiliogr [Internet]. 2018 [acesso em 05 abr 2020]; 110(2):124-30. Disponível em: https://www.actasdermo.org/es-actualizacionel-abordaje-manejo-celulitis-articuloS0001731018304253

15. Trell K, Rignér S, Wierzbicka M, Nilson $B$, Rasmussen M. Colonization of $\beta$ hemolytic streptococci in patients with erysipelas-a prospective study. Eur J Clin Microbiol Infect Dis [Internet]. 2019 [acesso em 05 abr 2020]; 38:1901-06. Disponível em: https://www.ncbi.nlm.nih.gov/pmc/articles/P MC6778588/pdf/10096_2019_Article_3625.p df.

16. Rodriguez JR, Hsieh F, Huang C, Tsai T, Chen C, Cheng M. Clinical features, microbiological epidemiology and 
recommendations for management of cellulitis in extremity lymphedema. Journal of Surgical Oncology [Internet]. 2020 [acesso em 05 abr 2020]; 121:25-36. Disponível em: https://onlinelibrary.wiley.com/doi/epdf/10.10 $\underline{02 / j s o .25525}$

17. Haalboom M, Blokhuis-Arkes MHE, Beuk RJ, Klont R, Guebitz G, Heinzle A, et al. Wound swab and wound biopsy yield similar culture results. Wound Repair Regen [Internet]. 2018 [acesso em 05 abr 2020]; 26(2):192-199. Disponível em: https://scihub.se/https://doi.org/10.1111/wrr.12629

18. Kisgen J. Antimicrobianos inibidores de parede celular. In: Whalen K, Finkel R, Panavelil TA. Farmacologia ilustrada. 6a.ed. Porto Alegre: Artmed; 2016. Cap. 38, p. 483497.

19. Araújo JM, Galdino M, Amaral SM (Org.). MRSA de origem comunitária. Residência Pediátrica [Internet] 2011 [acesso em 05 abr 2020]; 1(2):39-40. Disponível em: https://cdn.publisher.gn1.link/residenciapediat rica.com.br/pdf/v1n2a10.pdf

20. Unger NR, Gauthier TP. Antimicrobianos inibidores da síntese proteica. In: Whalen K, Finkel R, Panavelil TA. Farmacologia ilustrada. 6a.ed. Porto Alegre: Artmed; 2016. Cap. 39, p. 499-512.

21. Carvalho ESS, Ferreira JAS, Falcão MB, Barros DS. Erisipela: compreender para tratar. In: Carvalho ESS. Como cuidar de pessoas com feridas: desafios para a prática profissional. Salvador: Atualiza Editora; 2012. Cap. VIII, p. 159-76.

\section{Autor correspondente}

Arthur Alexandrino; Rua Santo Amaro, ${ }^{\circ}$ 111; CEP: 58.270-000; Telefone: (83) 996138749; E-mail:

alexandrinoarthurdm@gmail.com
Submissão: 2021-09-21

Aprovado: 2021-11-23 